\title{
Two museum visits in Lund, Sweden, and the streets between them: Accidental monu- ments between public and curated spaces
}

\section{Orestis Pangalos}

While visiting the Swedish city of Lund to attend the Conference Visual Semiotics Goes Cognitive 1 came across two of the city's museum attractions, the Kulturen Open air museum and the Skissernas museum (the latter is translated as the Sketch museum and also as the Museum of artistic process and public art). Borrowing from the walking-inside-museums experience as well as from wandering the streets around them, the following text unfolds by way of observations on the nature of museums, on the exhibited items and what we encounter in the streets. In this context multiple examples of artworks, related practices and emerging matters are discussed too.

Keywords

Open air museums, Art in public space, Lund, Street Art, Unintentional art

\section{Intro / Entrance}

Both the Kulturen Open air museum and the Skissernas museum (the latter is translated as the Sketch museum and also as the Museum of artistic process and public art) in the Swedish city of Lund deal in various ways with public space and/or the streets. This is the first thing I notice in any town or city: One reason for that is my background architecture studies, and another one is my street art studies, being a practitioner for nearly three decades myself. The following text is articulated in three parts, Visit 1, Visit 2 and finally The streets between and around the two visits.

Visit 1 deals with what was seen as a monument worth preserving by being transported and exhibited to a new setting. It is quite brief and mostly descriptive but a few of the elements found there will relate to the next visit's subjects. 


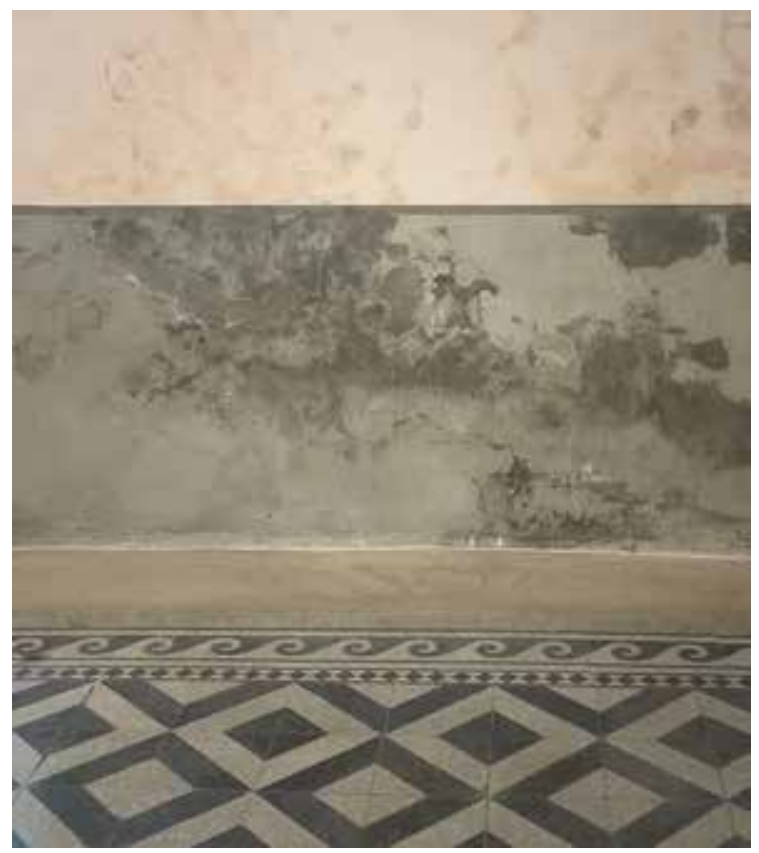

Figure 1: Detail from an interior wall in Kulturen Museum.

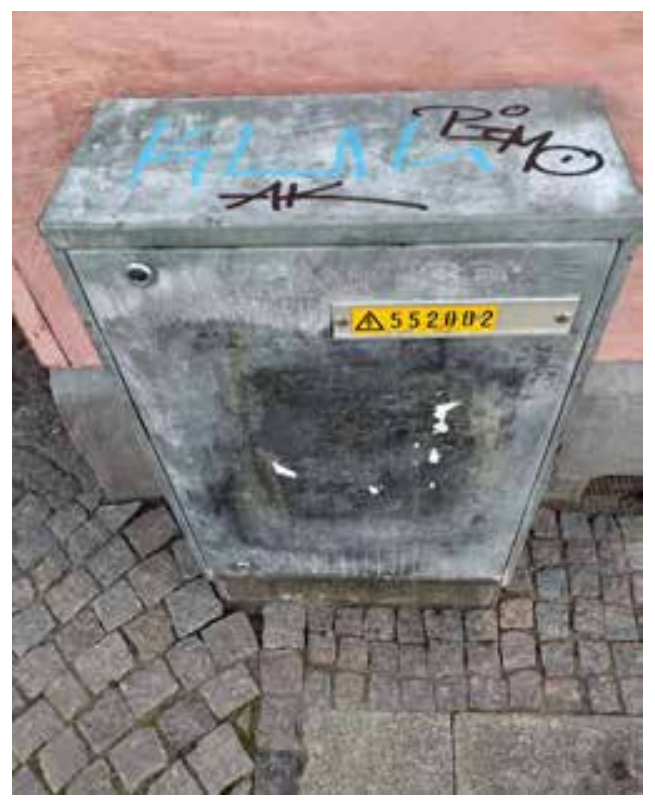

Figures 2: A metallic street box in Lund's streets.

Visit 2 offers a chance to look at graffiti and street art, and comment on their partial official approval and institutionalisation. 
The third sub-section takes a closer look at two city elements and their aesthetics that subsequently trigger relevant commentary on what will be described as unintentional art, but also on how artists have had similar approaches and observations in the past or nowadays. The two cases involve the traces on i) the traffic signs, ii) the telecommunication company metal boxes were the telephone cables connect servicing homes, workplaces etc. The process of the trace production is such that the result could be also described as accidental. The works produced by multiple interventions often offer a special aesthetic outcome that in any case is a basic typology of today's cityscape. The text underlies a central hypothesis about whether the objects that carry the various traces could be exhibited in the future as parts of a museum collection or in an open-air museum.

\section{Visit 1. Kulturen open air museum.}

Kulturen is primarily an open air museum, also including various permanent and temporary exhibitions inside the exhibited buildings. It extends to an area of two blocks that in a way resemble a village or a small town, a small district in the city center, or from another perspective a city within the city. It can be seen as a History, Architecture and Folk museum, as well as a Museum park all in one. Since about 100 years ago approximately 15 buildings were transported from other towns and settlements to the museum's location. Between the buildings themselves a whole new public space emerges, consisting of various sites and elements. One can meet gardens, sculpts, 'insect hotels', ponds, church bells, benches, old outdoor dance floors and various street equipment and public space typologies that one could find in cities and villages in past times. The buildings' exteriors themselves carry rich loads of information: the materiality of structural elements, the patterns schemed by the combination of construction wood, metal, bricks and stones, and ultimately the textures provided after the touch of weather, mush and time. The interiors, in many cases resemble the interiors of Swedish houses and workplaces representing aspects of urban and rural everyday life, in a range of the resident's activities and professions.

The journey was fascinating and the feeling was like walking in time-travel mode. However what captured my attention, were some ancient Runic engravings (Fig. 3) and the student's scribbles I found inside a 370-year-old church (Fig. 4). Right outside the building that functions as the museum's entrance, the visitors see large stones with Runic inscriptions on them. The Runestones date from around $1000 \mathrm{AD}$ and they were transported from various locations in Skåne. ${ }^{2}$ They actually are archaeological findings while the inscriptions provide historical evidence about the presence, the languages and the culture of the populations inhabiting the area. Another indication is the deeply rooted human need to trace their presence through writing on public surfaces. The other inscriptions I found were traces of recent activity. They 
date from the 1980s, and were most possibly written by students representing elements of their youth cultures. The old church in the Open air museum was built in 1652 in Bosebo and was moved there in 1895 with its full interior equipment, all of its decoration, paintings, sculptural elements and furniture. It serviced weddings, christenings, concerts and Epiphany vespers hosting the audiences of those events who evidently did not miss the chance to write on the seats and the desktops. The plethora of carved writings stay preserved together with the rest of the church and its elements as actual parts of the monument.

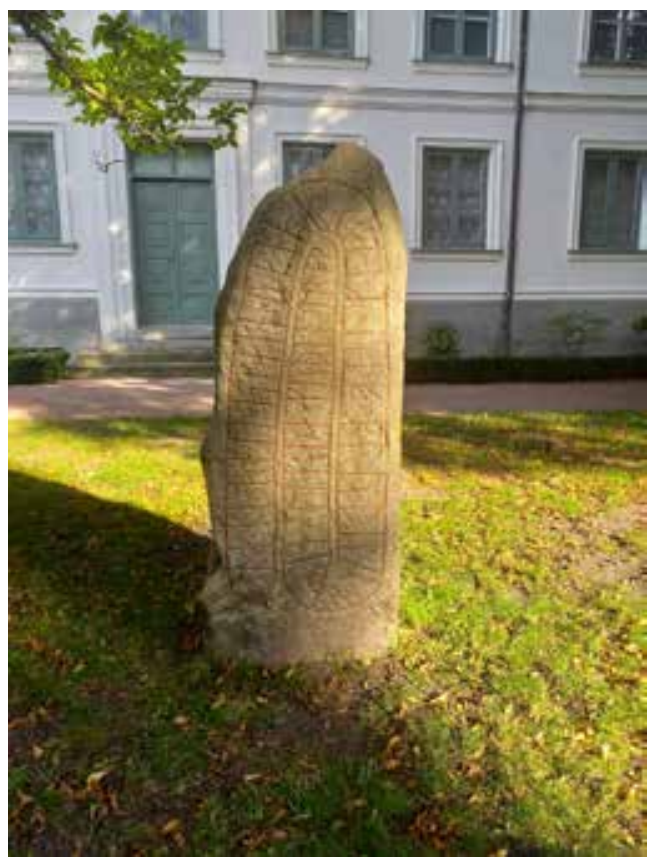

Figure 3: Runestone in the Kulturen Museum front yard.

There seems to occur a kind of twist here, regarding monumentality, memory and preservation. First comes the fact that the buildings did not make it to become actual monuments worthy of being preserved at their original locations. They were replaced by another construction. However, the mere acts of disassembling, transporting and finally reassembling-rebuilding them in their original form ultimately turns them into monuments, objects to be preserved, worthy of display and of actual historical commemoration. The various other smaller elements that consist the public space are also in this way celebrated as worthy of being saved, displayed and installed, and therefore have gained cultural value -in terms of aesthetics, design, function and overall significance, important for the museums mission to accurately represent past time objects and city streets imagery. In a sense, what was not conceived of as a monument on its original site, becomes a museum and a monument in the new location. 


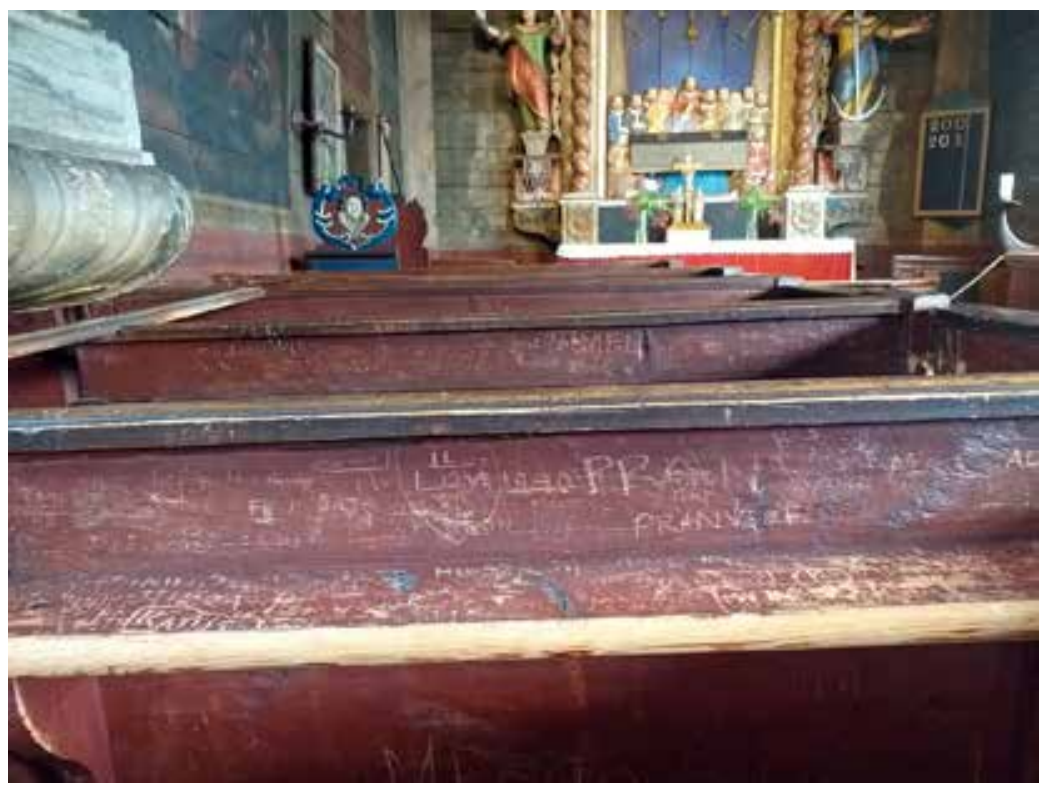

Figure 4: 1980s student graffiti in an old church interior. Kulturen Open Air Museum.

One such example that captured my attention was a 100 years old telephone booth with its elegant and dynamic design and graphics, the star in the center and the thunder-like arrows expanding to all directions. The central question became: What could be showcased in a future museum about today's street view and the image of the city? A set of possible scenarios will be offered later on, involving my street imagery, street art and scribblings interests. I could recall that in theater plays scenographers often use graffiti elements such as tags and pieces to create street references and scenes, in some cases even if the plays are about times and epochs when the New York graffiti style had not yet been born. Similar techniques are being used in film, and of course in advertizing.

\section{Visit 2. Inside Skissernas, the Museum of artistic process and pub- lic art.}

First evolve, the museum's thematic is sketches and scaled models for works that became artworks in public space. Many of those works are quite famous and often monumental - both in size and reputation. It would be fair to suggest that their display in Skissernas is in a way reversing and in fact complementing what the Open air museum is doing by bringing artifacts (sketches and models) and the whole picture (as a photograph) of monumental outdoor works inside. Artworks from all over the world are represented in the museum, thus they become 'museumized'. In this particular way they subsequently gain worldwide credit and even more 
value. Additionally their display recognizes the stages before the actualization of the work of art as highly significant process and celebrates the relevant artifacts as artworks too; turning them from private and sometimes obscure sketches to important items, accessible to the public, further elevating their importance, especially to the audience that is not much aware of the processes prior to the execution of a -large scale- artwork.

In the Skissernas museum one can also see various forms of street art too: not just in terms of official commissioned art in public space (such as sculpts, monuments, murals etc) but also of uncommissioned street art such as tagging, graffiti pieces, slogans, stickers, posters etc. In the Swedish section of the museum one can find exhibited tags on a frame as part of a painting by the native artist and graffiti writer Nug (Magnus Gustafsson). What differentiates this work from almost every other displayed in Skissernas is that his artwork (in collaboration with Carolina Falkholt) was not a sketch but an outcome as a review of their public art project in Mariestad Harbor silos (2010). In the museum's guide book the project is mentioned as the largest graffiti painting in the world. After the intervention the silos were demolished so the works -although commissioned- were destroyed too, as it usually happens with uncommissioned street works. Still, we should not forget that for the same style of tags (like those appearing behind the framed glass surface) the artist would find himself severely fined or even jailed if caught doing them in the streets -without commission. So, it seems that besides those legal facts and moral matters, some piece of recent graffiti had to be included in the museum. Actually, graffiti and street art (initially developed by graffiti writers) are ultimately largely recognized as the latest important art movements with uncountable works and massive participation. Last but not least, thy have also been a highly commercial exhibition genre guaranteeing popularity and attendance.

Of special interest is also the gigantic wheat pasted (and then painted over) paper cuts that monumentally cover two sides of the museum's courtyard. It reproduces the work by Brooklyn based artist Swoon, well known for her exceptional paper cut interventions in mid 2000s New York. The guiding catalog informs the visitors that the artworks are inspired by her encounters with refugees from Afghanistan and Syria, and that this as well as her other works and activities are part of community-based projects; ${ }^{3}$ they incorporate collectivity -and in that sense politics as well. One of the courtyard's sides is the former exterior facade of the older building before the Museum's extension. The museum's interior courtyard looks much like an exterior, or at least like a real city environment while the mirror ceiling that reflects the lightly colored floor intensifies this sense. Placing Swoon's work there strengthens this feeling, and in this manner it is representing a street art piece in an excellent play. ${ }^{4}$ Nonetheless, another 'installation' was set in the same space: Two long rows of tables and seats waiting for guests and the plates in place ready for the dinner to be served. The museum staff answered that it is usual to occasionally host some kind of event like that in the courtyard5. (Fig. 5)

This incident offers a chance to point out the limitations and dialectics of similar curatorial 
choices for acts once done without permission in the streets and now installed in the museum space: It has been noted that on the one hand such choices promote raising awareness, express tolerance for the reclamation of space and celebrate the free act of street art. On the other hand, they became subjects of institutionalization, assimilation and even exploitation. Depending to each given exhibitionary context, the artworks often loose their initial meaning and power, thus they cease to communicate their topics on a deep level. Crucial issues of critique, ethics and aesthetics arise here. However, Swoon remains an important artist to feature, her work vibrates positivity, the rows of tables are only temporarily placed there, and it was definitely not her decision to include them in the courtyard. A further comment might be necessary: Inside and around the courtyard a number of human-like sculptures had been placed. They were made by artist Maria Miesenberger (in 2005) and titled "Hide and seek". One of them is crawling away (Fig. 6) and another is ironically facing the wall turning its back to the dinner tables. Their placement was quite playful, they look as if they are escaping and hiding from what they see. To some extent, it could be thought of as a sort of curatorial commentary on the museums' own choices.

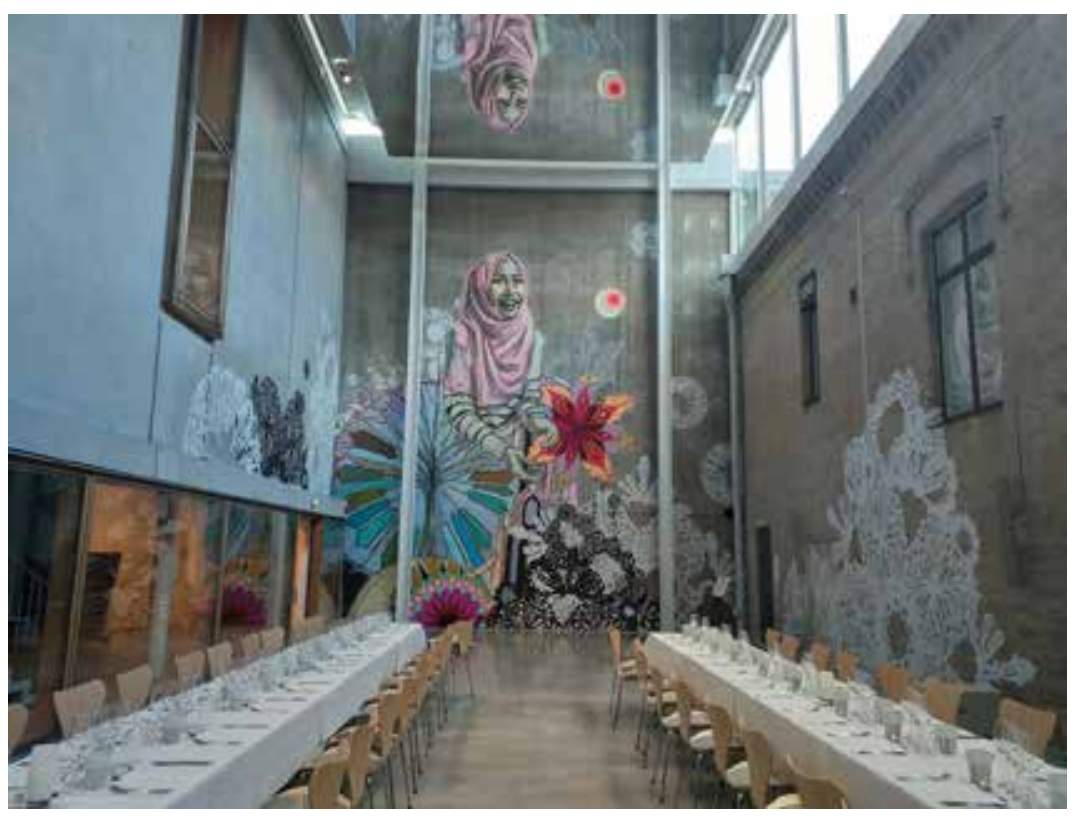

Figure 5: Swoon's 'Portrait of Maram' in Skissernas courtyard.

Among many emblematic artists and a politically oriented section dedicated to Mexican muralism, the museum collection includes works by iconic artists such as Jenny Holzer, Gordon Matta-Clark, Jean Du Buffet and Juan Miro who were affiliated with graffiti in various ways. Holzer started her work in the mid 70s New York when the tags and pieces were spreading. In 
the late 70s and early 80s she did participate in workshops together with young graffiti writers. Matta-Clark was one of the first to document early tags on subway cars (in the early 70s, photographing them and displaying them as artworks) in some manner equating the young taggers' works with his own -an act of great significance since the former's activity was constantly demonized as mere vandalism, nonsense and crime. He also invited taggers to write on his truck. He later cut it into pieces and exhibited a painted fragment of it as an artwork. Du Buffet's work was inspired by even earlier examples of graffiti, from 1965. ${ }^{6}$ The same is said for Juan Miro who has been caught in a photograph observing and admiring a kid's drawing on the wall. ${ }^{7}$ In several forms, not just as highly sophisticated and elaborate murals, but also as inscriptions and other kinds of street art, street works are part of the museum's belongings and featured items. Many decades ago the featured artists expressed with their works their appreciation and political acceptance of those forms/acts, probably much more clearly and in depth than museums are doing today.

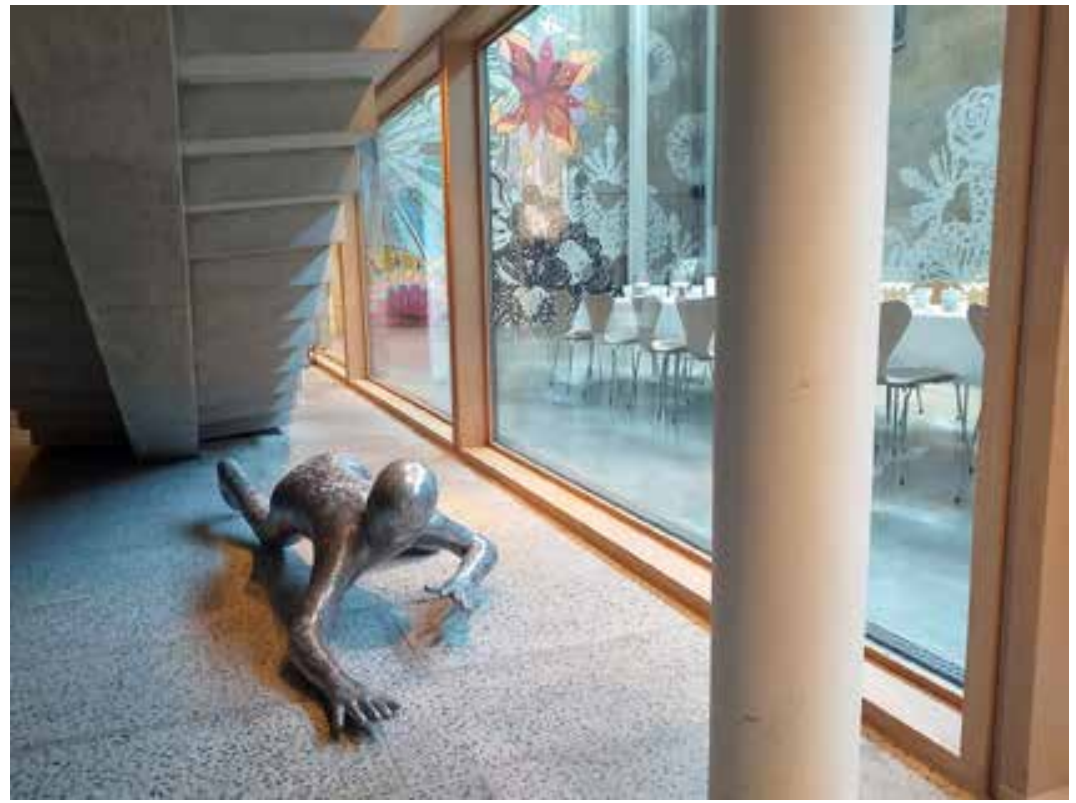

Figure 6: 'Hide and seek' by Maria Miesenberger. Swoon's wall installation in the background.

In a way, the dialectics of the acceptance processes could be sequenced as follows: free speech, resistance, non-legality, acceptance, tolerance, adoption, assimilation, appropriation, co-option, exploitation, neutralization, loss of initial meanings and total dissociation from signifiers. In a more dramatic style, the political could be distorted and turned into youthful exoticism, decorative ornaments while the artists could be transformed to brands. If that is happening now in museums -and long before that with the marketing and the cultural industries- it would make sense to wonder where are the politics in today's streets, or where might 
be the political art of today. If there is some acceptance of political art in the previous decades, what is happening now with today's political art; what are its forms and content, its techniques, strategies, mediations, and ultimately with its authenticity? Who are the subjects, the acting persons and the collectives who practice it?

\section{The streets between the Museums. The streets of Lund.}

A colleague quickly noticed and admired the tidiness inside the Centre for Languages and Literature building, compared to the polyphonic but sometimes quite messy look of University facilities in Greece. He found no political posters on the interior walls at all. Is there any politics here, one wondered -or is it just secured in the Skissernas museum as works of the Mexican revolutionaries, as acts of the glorious sixties and seventies, and maybe the eighties too? By taking it to the street level, was it really like that, so disciplined, 'protected' and ordered as it appears today? Walking in Lund one can witness various posters of all kinds placed in selected spots such as the dust bins, the telecommunication cables metal boxes, the post office metal boxes and so on. They were not spread all over like it is happening in Greece but they were definitely present and evident. Additionally, so as to not saturate the city, they stood out making a difference to the otherwise ordered public space.

Lund's walls are quite tag-free. The tags are not really many, not because they are not frequently written but mostly because of Sweden's zero tolerance policy on graffiti according to which they get wiped out systematically. ${ }^{8}$ What one can see out there is the few tags remaining mostly on top of the originally grey metallic boxes mentioned above (Fig. 2). Those boxes' surfaces become an ideal host for tags, poster pasting, plus for every kind of stickers. Sticker pasting was a crucial practice in the advent of the so-called street art in the late 90s and early 00s, but also a 'vehicle' for advertizing practices and propaganda too. The poster pasting predated the aforementioned functions. The other surfaces that the stickers mostly occupy are the green columns on which the traffic signs are adjusted. There are innumerable stickers that have been stuck, removed, re-stuck and half removed from those usually forest green-colored objects (Fig. 7). In this essay's study, objects like the grey metal boxes and the forest green metal columns can be seen as the 'bearers' of the media and the 'canvases' of the sings. I would suggest that the media are not only the tools, the materials, or the act (in this case graffiti, street art, flyposting as acts and as media) but also the surfaces and the objects, be it walls, boxes, columns, street sign boards, benches and so on. Just as it was rocks, bricks or trees in the past. Name writing, message writing and drawings of any kind are in a sense one of the oldest forms of communication to date, and the walls and objects they appeared on are of the oldest and primary media.

The act of their mere placement can in many respects be called political as it embodies 
elementary forms of appropriating space for free speech and expression. But even besides those acts and the content of the messages, the sole act of their censorship and defacement could rightfully be considered political too. ${ }^{9}$ After all, they present particular trends in graphic design and visual communication, potentially ranging from the most mainstream to the most underground. The verbal poetics is another topic worthy of extended examination. ${ }^{10}$ However, besides subjects, themes, words and graphics, I also found a special interest in the unintentional forms produced by the censorship of those messages; the defacement of the stickers, posters and tags (that are anyway officially deemed as defacement and vandalism in the first place). Eventually, the defacements often result in compositions of various elements such as tags, torn posters, paint, paper remnants, half washed out paint and patinas: multilayered palimpsest forms, all unintentional collective visual productions.

The visual manners, the imagery and the language used in those stickers can anyway be further researched and analysed. They involve a plethora of sings and subject matters, and whatever comes from the everyday; from politics to football, from gender issues to social movements, from live gig posters to free radio station broadcasts, from demos to assemblies, from marxist to anarchist approaches, from collective affairs to any kind of personal taste or culture or group one could belong, from personal artworks to scientific conference logos. ${ }^{11}$

As noted, those stickers and posters are also evidence of politics going on consisting an important collection of artifacts for their verbal and visual languages as well as proof of symbolic actions of claiming public space beyond the law. At the same time, they are somehow honoring and continuing an older political tradition that is often celebrated in museums ${ }^{12}$ or in documentaries broadcasted in the national TV networks. Thus, they are equally important and deserve a documentation for the same historical and cultural reasons as well as for the aesthetic ones explained earlier. They are worthy of documentation both as photographed pictures and as physical collected artifacts. Nonetheless, an urgent reason for a consistent documentation is their very ephemerality. In most cases they are shortly removed and destroyed, or maybe (especially in the case of posters) over-layered by another installment. Soon after, the larger picture changes.

Another aspect worthy of analysis are the forms and textures created by the stickers' and posters' partial removal; the remaining traces after their defacement. The action of removal introduces another factor, the persons and authorities who deface. The stickers' glue must have been very strong unless the removers were not patient enough -whether they are municipality and campus workers, ${ }^{13}$ or independent individuals. Even if the printed surface layer of the sticker gets detached, a layer of glued paper still stays on the metal surface. So, much of a random texture is left on the objects, creating abstract shapes and a variety of textures. The visual result -whether of a composition of torn stickers or of a single sticker- in some cases is very interesting for some observers. Additionally, if one looks more carefully, one could see that the white paper that remained glued, was fertile ground for short vegetation like mush. 
Similar tints are produced on the metal telecommunications boxes too, only this time it is the wheat paste glue that dissolves the boxes' primary grey or silver paint. Thus the removal of the posters reveals the newer patterns on the surfaces. In the end, what we see is an accumulation of actors, factors, processes, actions, materials and images all incorporated in a new image.

Since these objects are unignored elements of the city that bear specific messages and particular aesthetics the question finally returns to the initial hypothesis about whether they could be preserved and showcased in a future museum; as designed objects for a specific function in the first place, that on the other hand serve as the surfaces to host taggers' calligraphy, arty stickers, students posters, political messages that are visualized accordingly with the use of an extended vocabulary and imagery. Still, many might reasonably ponder whether it is serious or worthy, or if there is any real value in such a possibility. Nonetheless, whatever the response is, it is happening now, it indicates an activity, involves loads of information and evidence for further research, and in many respects appears to have certain aesthetic qualities too.

\section{In praise of textures}

It is true that such results have been witnessed in other cities as well. However, in Lund I can say that what remains after the removal of the stickers is a basic typology of its streets' image. A similar phenomenon occurs on the metal boxes: marker and aerosol paint tags blend with poster remnants, overlapping stickers, and the traces that the poster glue leaves to the prior surface when 'eating' parts of the boxes' official paint. At first I wondered whether my observations on the aesthetic outcome were that rare but I quickly realized that one might easily find similarities with older images from torn up posters and collages in the History of Art, as well as in popular culture. First, the textures provided by the half-removed sticker traces in some cases look like the patterns created by the random fluid acid textures in many etching prints. Secondly, the metal boxes' compositions are reminiscent of Dada collages or Abstract Expressionism paintings (Fig. 11). Similar textures were definitely not ignored by many artists' sensitive eyes and this is what their work certainly prove, for instance Rena Papaspyrou from Greece who diligently observed and photographed close ups of marbles, mosaics, or/and other tints created on aged walls ${ }^{14}$ (Fig. 8). In a similar manner one could find similarities between the sculptural artwork that is adjusted on the exterior of Skissernas museum resembling the globe (Fig. 9), and the round-shaped moonlike stickers remnants on the traffic signs close by (Fig. 10). Taking it to other corners of the art-world, this charm was exactly what artist and filmmaker Dennis Hopper intended to capture with a series of photographs: fragments of spray painted tag lines, as if they were some professional artist's gestures carefully placed on the wall's rich textures in composition with torn poster remnants (Fig. 12). 


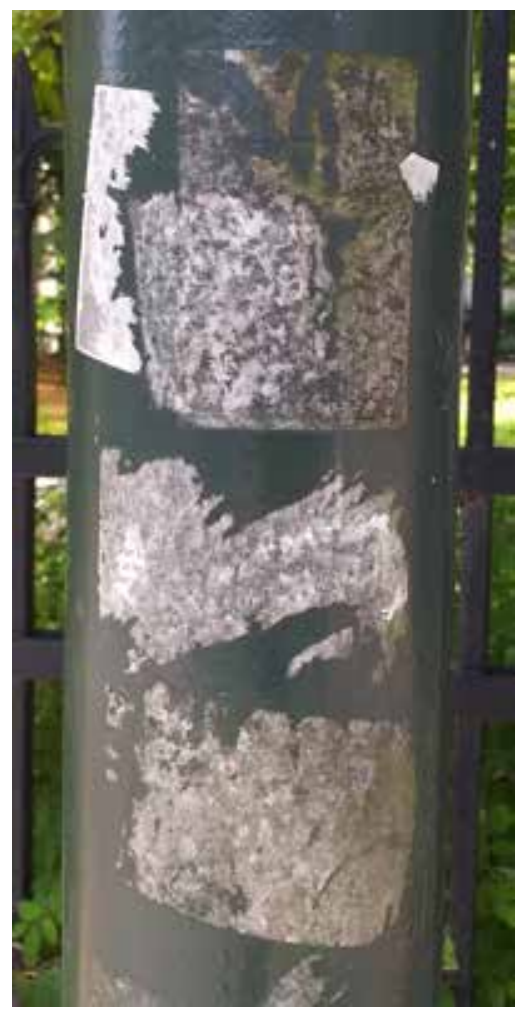

Figure 7: Sticker remnants on Lund's street signs columns.

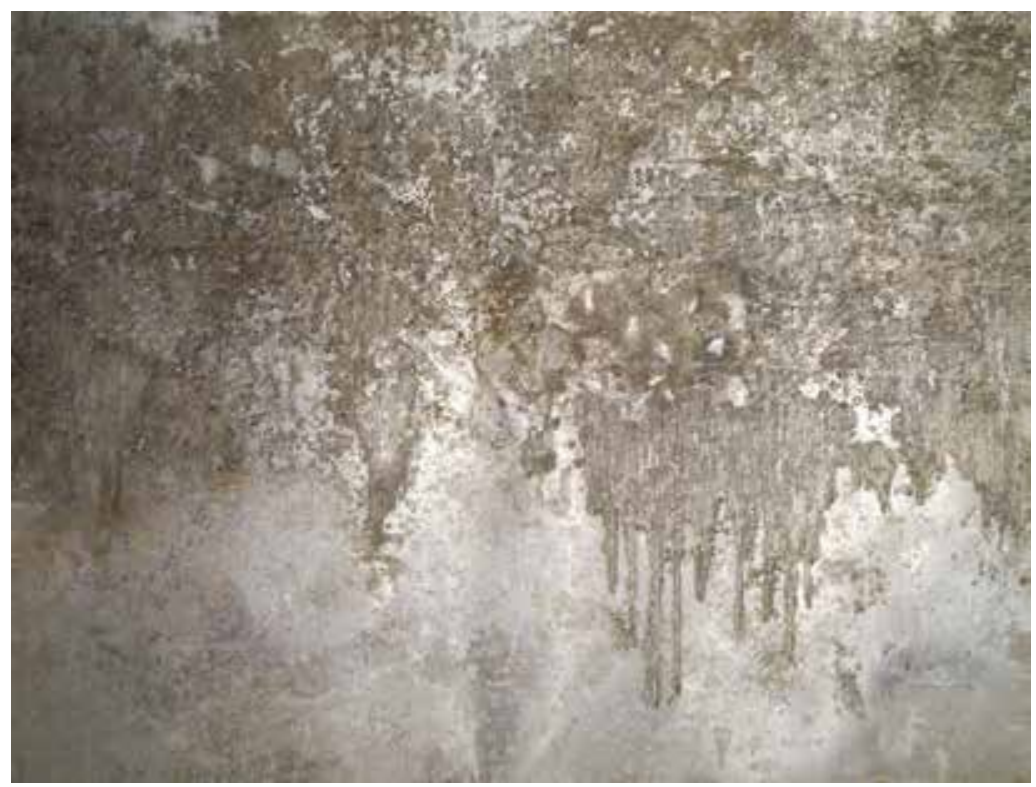

Figure 8: 'Geography', Rena Papaspyrou, 1981. Metal sheet with traces if cement, intervention with pencil, $270 \times 100 \mathrm{~cm}$. This particular picture was displayed in her own book front cover. 


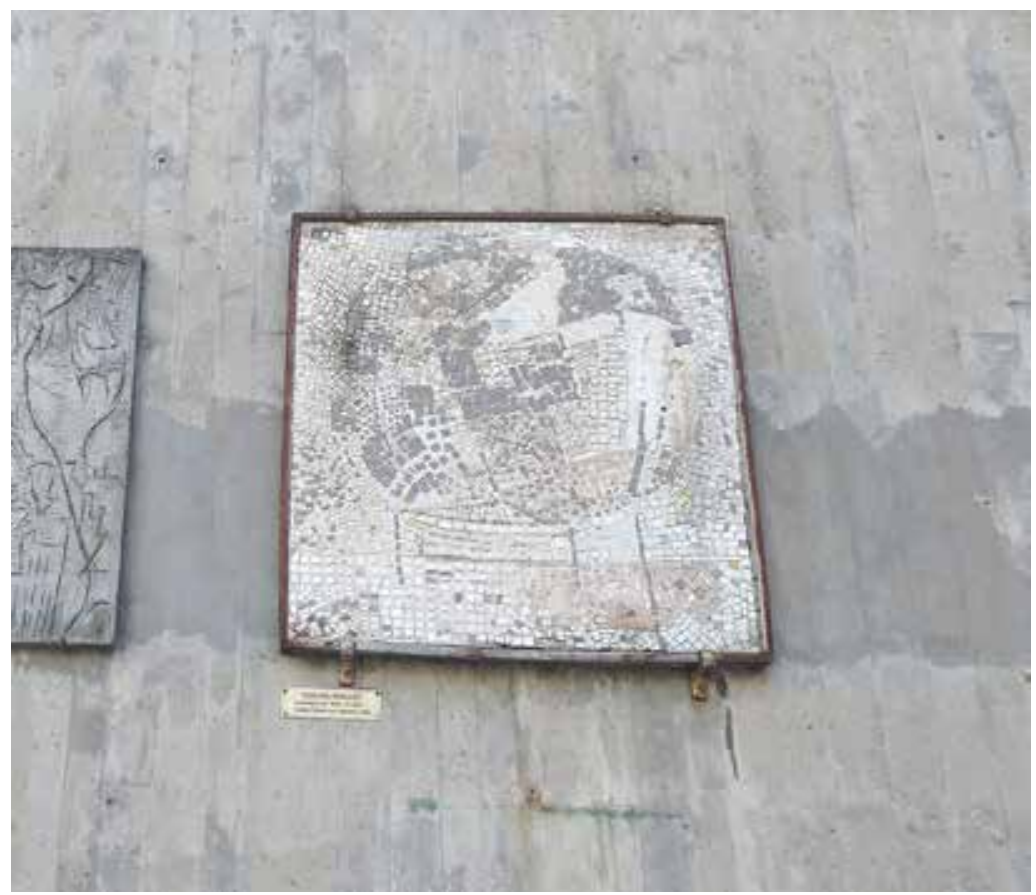

Figure 9: 'Glob en vand', Torsten_Renqvist, 1958. Installation on the northern wall of Skissernas Museum.

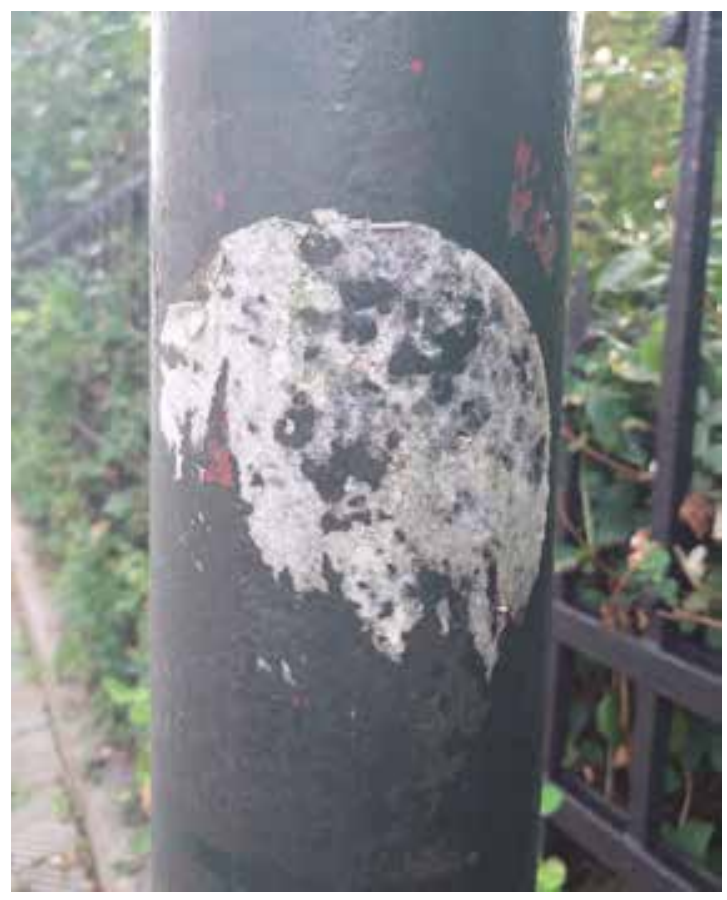

Figure 10: Sticker remnant, Lund 2019. 
Textures have always offered some kind of 'unexplained beauty'. From my studies at the School of Architecture I remember that restoration we should respect the principles of buildings and paintings under restoration. They are actually important because of the trace of time -and this is what on is found a smaller scale in Lund's boxes. The aspect of time is there in all its splendor: textural surfaces like artworks created 'organically' by the multilayered human touch, that finally combine with the elements of weather and in some cases with vegetation; on the ground, on the walls, on various materials, and of course on the paper remnants too. Take mixed media products in a process of aging through a somewhat organic growth progress, where even the sunlight reflections or/and the humidity contribute to the whole picture and its feel. Photographers often choose old walls for their textures, their pigments and their gradient colors. In fashion photography models frequently stand in front of them. The textures add to the scenery's aura, and finally to the overall essence of the picture. Additionally, when a tag is included it is even more credible. The now invisible body of the tagger is left to be imagined: an unidentified street persona who left her/his mark at some moment, possibly during nighttime. Decorators in shops often try to artificially imitate textures, and more recently coffee shop owners do their best to preserve the original ones. In Paris some fifteen years ago friends explained to me how a formerly overcrowded Parisian cafe lost its character and its customers after the owners decided to renovate it transforming it to a freshly painted neat looking place. In the last few years in Athens when new bars open in formerly empty stores the decorators often act 'as if it is a crime' to paint over the textured and tagged walls where time has left its mark. Especially on the ceilings, a usual material of choice is simply a transparent varnish that emphasize the oldness of it. They seem to respect them as they would respect an aging wrinkled human face. But besides, behind and beyond this late trend, there is much depth and tradition. Such examples remind us the soulful and sensitive approach in Junichiro Tanizaki's famous book In praise of shadows, ${ }^{15}$ possibly a quite suitable analogue to this conversation; a full insight to how shades, shadows, textures and patina makes a surface look alive contrary to a lighted solid painted surface that lacks traces, 'information' and interest. One could say there is some shared universal respect and intrigue to the textures, aesthetics and time-processes like the ones described above.

\section{In praise of tags}

Past forms of tagging are seen as historical evidence and so many old tags are considered worthy of being preserved. A famous tagger was Lord Byron. Less known for his tagging habits was Victor Hugo. ${ }^{16}$ Guides do not miss the chance to point out Byron's carving on his name on the temple of Poseidon on Sounion, Attica. In Switzerland's Chateau De Chillion, his tag is protected by a glass framed in metal so that it stands out from the rest of the carvings. ${ }^{17}$ One 
might think it blasphemous to compare anonymous taggers with famous personalities but you can never really be sure who is who and how to evaluate what she/he did with her/his life. For example, a New York tagger from the 70s was awarded a Pulitzer price when he grew older. He was a member of the famous crew The Crazy 5 (including graffiti legends Blade and Comet) which was quite important for the history of the movement for its innovations, quality and quantity. ${ }^{18} \mathrm{He}$ is not the only such example: Think of tags by tagging pioneers Phase2, Lee $163^{\text {rd }}$ or Taki 183 that would all be of indescribable importance. Many would agree they would be worth a plexiglass cover protection placed in front of them. Their marks, as it has happened with Hugo and Byron. Guides would no way miss them in the lately popular street art tours, or other kinds of cultural tourism and city walks. Maybe a hundred years should first pass for tags to be fully appreciated but the difference here is that their names are not carved but painted on the surface so it is impossible to wait that much before they 'get buffed' or fade out. On the other hand, writers and tag aficionados do keep places with old untouched marks as their own secret monuments: hidden sacred "hall of fames" of surviving tags in places such as tunnels, rooftops, bridges and other passages that are usually not frequented by pedestrians and officials, so they have not been erased.

In some cases though, tags survive when written on objects or paper and their status is high since they are pieces of history and memory. For example, the lavatory door from the early subway writing movement researcher Jack Stewart, is exhibited as a rare artifact ${ }^{19}$ and carries an extreme importance regarding the movement pioneers' signatures written on it. Martin Wong's collection of early pioneers' tags, each written on a small piece of paper, was recently displayed in the City Museum of New York loaded with the same or even more value than the paintings on canvas of the same exhibition. ${ }^{20}$ Gordon Matta-Clark's metal piece of his truck stands like an archaeologist's finding or a collector's ultra rare item; like an 'urban ruin', a unique piece of history from the early '70s South Bronx environment and culture.

Returning to Dennis Hopper's photographs, one of my early personal encounters with an 'outsider's' appreciation on tags was his unique perspective described earlier. In a retrospective exhibition at the Stedelijk Museum (Amsterdam 2001) visitors could admire fragments of enlarged tags on a monumental scale exceeding the height of the spectators. The detail of the enlarged lines fading in and out were impressive, as were the curves and angles schemed by the taggers' gestural moves and the release of spraycan paint under pressure. That was surely an arty touch on the wall, somehow regarded as a professional calligrapher's handwriting or an abstract expressionist's masterpiece and it was debating strongly that -now outdated- 'art or vandalism' binary. It was art because -luckily- Dennis Hopper thought it is, and because this narrative was part of a high status museum exhibition. Additionally, it celebrated not some established person but an anonymous artist's tag, a gesture that could have been made by anybody out there. 


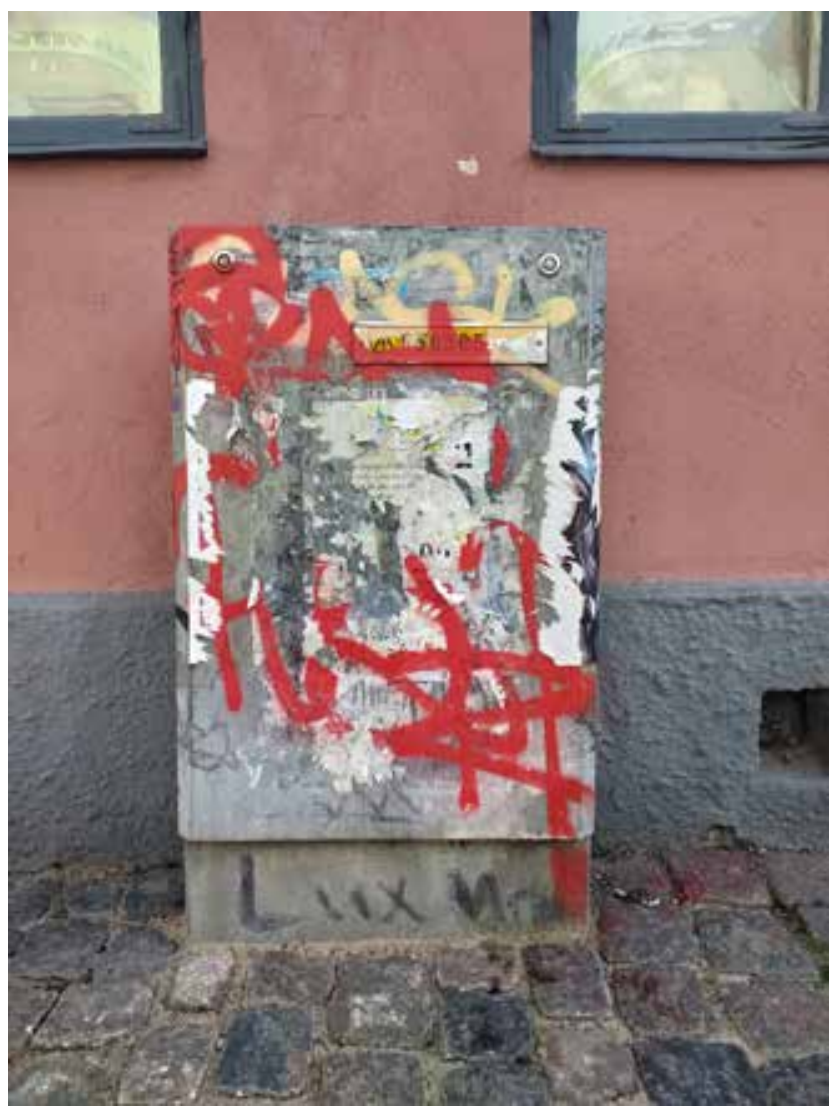

Figure 11: Tags and posters remnants composition on a metallic street box, Lund 2019.

\section{The empty signifier}

But there is more. In 1976, in his book Symbolic Exchange and Death, Jean Beaudrillard included his observations on the early tag signs. When I first heard that he had called the tags empty signifiers I had felt uneasy. My lack of familiarity with semiotic terminology wasn't helping me understand what empty meant. How could somebody ever claim the tags were empty of meaning?. That was my serious objection ignorant as I was to the fact that 'empty' meant 'open to multiple interpretations'. Despite the fact that the graffiti writing movement was still too young to be interpreted when Beaudrillard wrote about it, he seemed to have had a deep understanding that there were many signifiers that remained unidentified by the general public, including academics, journalists and the art world. In his insightful text, to my satisfaction, I read that although "their content (of the graphics) is not political", ${ }^{21}$ "the political significance of graffiti becomes clear".22 


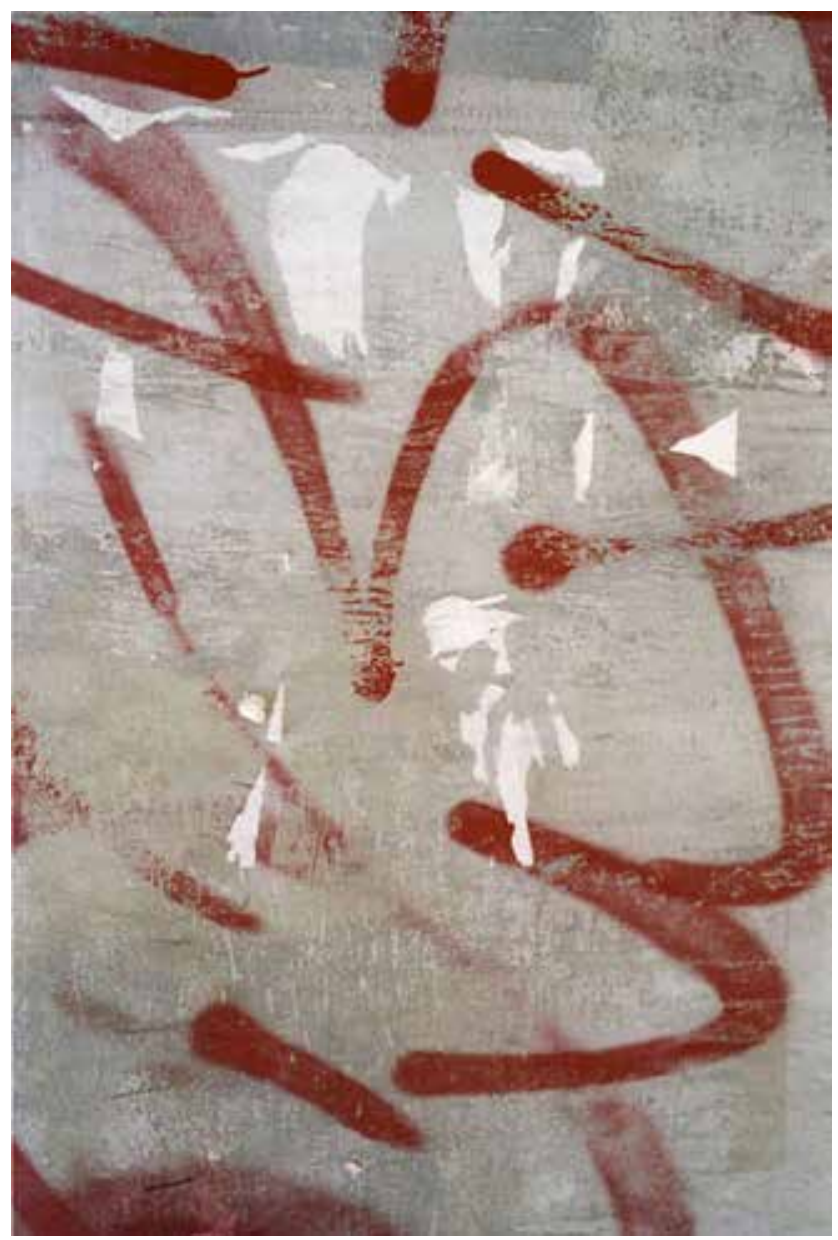

Figure 12: Dennis Hopper, photography, Florence 1996.

Author Dumar Novy in his monograph What do a million Ja tags signify? about legendary New York tagger Ja (who has been unstoppably tagging New York City for more than 30 years) he summarizes the very essence of the graffiti spirit. At some point the author argues that Ja's one million tags can be used for one million interpretations, but in his own special manner Novy certainly reveals a good selection of them in various poetic metaphors. Based on Ja's devotion we read "Ja is what Marcuse advocates for in Repressive Tolerance, is what Ginsberg was jiving about in Howl, is the last word scratched in the prison wall by Guevara \& proves most of what Marx wrote". "Ja is a different take on Bob Ross painting nature (...) [Ja] is painting a portrait of every single happy little resident of the city with his spray cans"." Ja is Vietnam". ${ }^{23}$ Resistance, howls, revolution, economy, politics, city life, happy faces, smiley people, war. In the Arte TV Channel episode series Ceci n'est pas un graffiti the same author concludes that 'graffiti signifies life'. ${ }^{4}$ According to New York pioneer writers of the 70s the tags were an extension 
of ones' style having a certain touch of personality; they were 'flying and singing', it was about who you are and what you are doing, to whom you are up together and down with. ${ }^{25}$ Tags were the Voice of the ghetto (as Stay High 149 use to write), they were anti-segregating and overcoming barriers, ${ }^{26}$ while European teenagers of the 80 s and 90 s were adopting tagging, graffiti and hip hop as totally antiracist practices and cultures.

Bringing it back to the late $19^{\text {th }}$ century, former Mayor of Chicago Carter Harrison was one of the many hundreds who were writing their names all over, for instance on Ancient Egyptian monuments. He was criticized for that but he defended himself publicly in his travel letters published in the Chicago Daily newspaper: "By the way, sensible men justly inveigh the habit of 'vanity' in carving [their] name upon monuments and thereby defacing them. But there is sense in cutting one's name upon imperishable rock without defacing it. Some may come afterward, and, seeing it, feel as if meeting an old friend. My heart was warmed up here in Egypt when seeing the names of some old acquaintance now dead. I felt we were living over again a half-forgotten past.' I saw 'Jenny Lind's' name upon the pyramid. Did she (...) for a moment there come from the West, over the dead desert, a trill of perfected harmony ..." ${ }^{27}$. Memory and communication come to the surface. Friendships and networks of people, love and affection, persons and life stories, traveling the worlds, traveling the cities, all of them aspects of today's tagging which found an unexpected defender in Carter Harrison.

\section{In praise of the unintentional, accidental art and its documentation.}

So far, a number of works, their ingredients and substances have been discussed: stickers, posters, tags, objects, contents, meanings, and their visual results too; organic, palimpsestic, dynamic multilayered compositions, that contain fragments of words, dates, typefaces and handwriting that include various images and cultural references. provide textures and accidental unintentional results of certain aesthetics that in many respects they can be seen as art.

Already in 2001, such an approach to unintentional outcomes was documented and discussed in the film The Subconscious art of graffiti removal. ${ }^{28}$ The filmmakers traced a good number of erased tags painted over with square surfaces of various dimensions and colors that eventually created compositions close to suprematism, minimalism, abstract expressionism and the Russian avant-gardes. At that point it was a really insightful contribution on the unintentional forms produced after the primary graffiti act and what follows after the traces' removal that are actually replaced by a subsequent mark. The 'buffers' -as they are called in the graffiti dialect- rarely succeed to use the same color on the wall beneath the tag, so they also create another trace in public space, usually orthogonal with its dimensions and proportions depending on the original tag or 'throw up'.29

However, when I visited the Unlock book fair in Cologne ${ }^{30}$ I found out that a book with a 
similar approach existed: Rail experimental - Belgian train worker art actually showcases what remains after the partial removal of graffiti from the train's exterior surfaces. The workers use a chemical solvent that dissolves the graffiti paint but in the case that they do not totally remove it, it then transforms to a layer of smudged colors where the workers gestures can be traced too. Furthermore, the chemical sometimes dissolves the train's original paint or even the train company logos themselves. ${ }^{31}$ But that was not the only publication of an 'unintentional art' documentation showcased in the book fair.

A second one directly travelled me back to Lund: In Lund, in contrast to the near absence of spray-painted tags on the walls, I had noticed another sign of spray-painted patterns, only this time on the ground -just a few hundred meters from Skissernas. After wondering for a moment, I quickly realized it was workers' signs who had marked the ground offering directions to the next shift of workers for the digging of holes, repairing the pavements or for other kind of constructions to be made. But a second thought came as fast: Could it be some kind of a conceptual street art project? Observing more carefully I assumed it was real construction work signs. Later I encountered more, similar markings connecting to ongoing constructions in Lund's streets. However, back in Cologne, the book I saw was firstly documenting such marks and secondly it presented what a graffiti backgrounded artist did on the ground: he got obsessed noticing and documenting them, then he got inspired by them, and finally he proceeded imitating the workers' lines and schemes in his own style camouflaging this way his non-legal tagging practice. Additionally, he could do it in daytime wearing a fluorescent worker's vest acting like it was a commissioned and necessary activity. As an accurate and playful description the book is titled Out of Necessity with double connotations: the workers' marks, and the artist's needs. ${ }^{32}$

The two books mentioned above help us underline another aspect of the graffiti game: Graffiti writers besides being artists are at the same time archivists, documentarists, researchers, as well as historians and critics of their guild's works. Additionally, many of them show deep interest and also document any other relating activity in public space, and processes of placement and displacement. In many cases too, they are collectors of the various artifacts from the street and the art in the streets universes. If they can, they would collect whatever possible and some of them maintain rare and unexpected collections of objects. Many of their private collections are contemporary cabinets of curiosity, capable of articulating complex exhibitions and even supporting whole museum concepts. Like archaeologists who seek new findings, like biologists who discover new species or like the $19^{\text {th }}$ century flaneurs who are 'the botanologists of the asphalt', similarly so many graffiti aficionados are the contemporary botanologists of the vertical surfaces, their paint, their inscriptions and their textures in any kind of given public space, urban and rural too. Documentation and publications have always been important in initiating further discourse and developing. On the one hand they immortalize the ephemeral works by nature, on the other by mediating them they reach and influence 
non-local and international audiences. ${ }^{33}$ Furthermore, the only real graffiti and other work of uncommissioned street art are the ones that happen in the streets, ${ }^{34}$ and the only real actual works that make it to be exhibited in museums are the ones who are displayed as documented material in printed photographs or videos. Of course, the photographs and videos are themselves representations of the physical works. However, they still display the images of original ones that have been a result of a particular action in public and private space. That said, there can only be very few exceptions of real street art featured in exhibition spaces: one of them is by detaching a whole written/painted surface (from the streets) and finally transporting it to the exhibition space. If the work is not directly painted on the surface but first on a sticker or a poster, then their removal can still make them stand as real artworks that were detached. A second way to show street art is to display the works from the streets on actual exhibited objects who were once the bearers in the real streets. Afterwards those objects are removed as a whole (collected, stolen or even bought) by somebody from their original location and are finally transported into the exhibited spaces.

A last couple of examples will hopefully push further what has been discussed so far: The first comes with the recent publication Punk Graffiti Archives: Madrid, which introduces the largely unknown indigenous punk tagging movement from the mid 80s. Many of the pictures displayed in the book are real tags written on billboard paper. They survived physically just because they were cut out from the subway billboards and thus collected and still existing. ${ }^{35}$

The second example comes from Rotterdam in 2001 when the local sticker and street art scene was blooming and the term street art had not been coined yet. An international movement was emerging through artists with graffiti background and the Rotterdam scene was having an impact with serious contributors. Artists Erosie, Space3, Influenza and others organized an exhibition/event called 'Public space expo (p)art(y)' on a most possibly squatted the occasional spot - or at least a place that didn't look official at all. The poster itself displayed an illustration of the city's waste bins on which their stickers and paste ups were placed on, however the spotlight seemed to be on the bearer-object image. In the exhibition interior spaces of the otherwise empty building, among paste up installations who were covering entire walls, ${ }^{36}$ a series of extra sized street waste bin images were dominating the various rooms walls. Nonetheless what mostly stayed in my mind and is still rambling until this text was a city element placed in the center of a room; in the middle of living room sofas and people hanging around. It was a mid-sized street column, like those preventing vehicles to enter parks but a bit higher, bearing a big variety of the stickers that were an element of the city landscape at the time. Yet on an underground level they were paving ways to what globally boomed as street art in the following years. Also, reflecting on their contemporary practices, they indicated the value of an object as a medium, and as an item worthy of being preserved and exhibited then and in the future. 


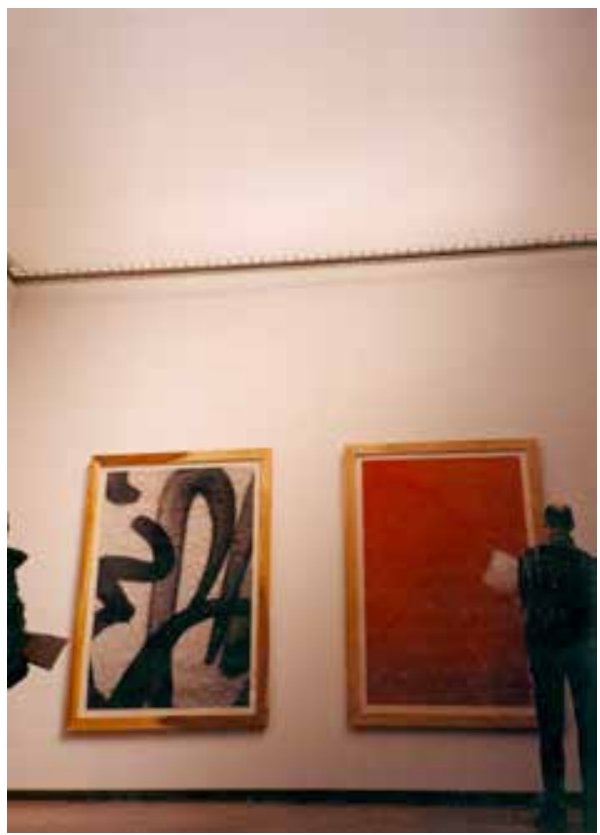

Figure 13: From his exhibition in Stedelijk Museum, Amsterdam 2001.

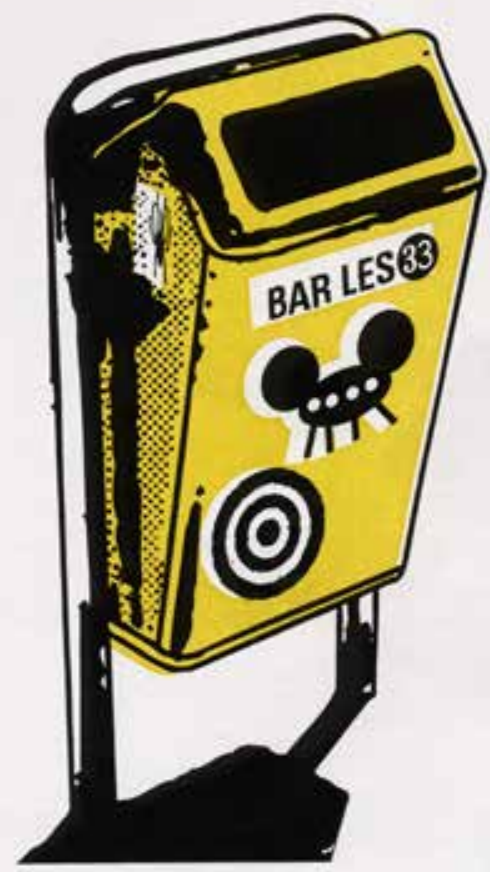

Figure 14: Image from the 'Public space expo (p)art(y)' flyer, Rotterdam 2001. Courtesy of the author. 


\section{Outro / Exit: A long stroll and its afterthoughts}

What I have tried to explore in these final pages are the aesthetic processes of unintentional art in public space, as well as the removability and transportability of such street works, for example by detaching a sticker off an object, or by removing the whole object itself, like a real truck, an actual street sign, a real door, a whole bench or at least parts of them that bear a sticker, a poster, a tag or all of them in one. In other cases, it could be the removal of a whole wall surface made of wood or plasterboards, metal fences, shutters, tiles and so on, or in the most difficult cases, parts of a heavy brick or concrete wall. The starting point for those explorations was the experience in Kulturen Open air museum and the Skissernas museum of artistic process and public art. Together with the streets between and around them they triggered the initial hypothesis of what forms could be proper in order to represent the current epoch's streets, atmospheres and trends (in Lund but also in a universal perspective too) and if it would make any sense to include (in a museum exhibition) items such as a traffic sign column full of stickers or a metal telecommunications box bearing the collective products of what we have called unintentional art compositions.

Of course, the question is totally hypothetical, but according to the examples, facts and anecdotes explained above we could suppose it is fair: There is a tradition of sensitivity and appreciation of the aesthetics of textures, and there are approaches to the unintentional production of art. There is also a serious recognition of the significance of tags. Street art in its various forms, idioms and expressions has been recognized at large as an important influential movement which is highly commercial in the same time. Most of the topics discussed here are part of the urban aesthetics who is also a subject of high interest. ${ }^{37}$ Regarding all those factors it can be suggested that the hypothesis makes sense, and maybe a similar project or plan is already happening in some place of the world.

However, even though I find the idea interesting, there is no guarantee any such effort would be necessarily successful. If for a while we forget Kulturen and Skissernas (institutions that take serious care of their material and curatorial responsibility) for any such ambitious project, a series of complex matters arise at once, matters of curating, knowledge, work selection, sensibility, credibility, representations and authenticity. At the same time, matters of context and respect of the artists, their works, as well as of their politics, ideologies, cultures and historicity, and also matters of research, aesthetics and ethics. Of course, the hypothetical nature of the question leaves open who the organizer would be and what would be the occasion of an exhibition or the wider concept. There could never be a specific 'manual' covering all these matters.

A set of technical questions still remain: Besides collecting them, who would save and store all these items, and cater for their preservation and maintenance. Considering such questions as well as the historical tradition of people collecting various artifacts, I would suggest there is 
a high possibility that many people collect this kind of items. There are definitely many who document such examples of works. Yet who would initiate an exhibition like that? One could think that the same kind of academic motivation and dedication that initiated the founding of Skissernas museum nine decades ago, could officially work in a similar direction. In a different perspective there could be other viewpoints and goals, thus other strategies to promote and create demand for similar projects. A promotional campaign could work, but regarding the essence of the subject nothing guarantees the consistence of the topic with its final exhibition outcomes. Also, the same marketing tactics could certainly include specific 'stars' in the field (as it happens with many of the street art themed exhibitions) most possibly excluding credible works, as well as the anonymous and unintentional ones too. Leaving aside the otherwise long debate about similar projects' necessity, one should also keep in mind that all those street works we are talking about were initially not made to live forever, and they were not created in order to become future exhibition items. Furthermore, their representations are not authentic works.

A last subsequent question follows. As mentioned above, there is a long existing tradition of collecting artifacts among people with street art backgrounds. So, it would be of exceptional interest if artists and/or some of their friends could present their collections to multiple audiences. Each one of them can potentially be a curator of her/his own archives and collections, in a way promoting a museology of personal archives, at the same time consistent with the self-education tradition of various street cultures. We should keep in mind that such efforts guarantee nothing as regards their final quality standards. We should also not forget that in some cases it still remains very hard and often a matter of privilege to preserve these artifacts, especially the heavy and oversized ones. The question (and the real challenge) lies in whether the same do it yourself ethos together with honesty and loyalty, deeply rooted in the years of these subcultures' birth and evolution, could create some equivalent in the ethos of display. In that respect, such endeavors would offer the chance for further first-hand testimonies, narratives and histories of the works, the art forms, and their cultures. Furthermore, their own perception of the city image, and their perspective on the urban memory and experience would form alternative narratives for a richer understanding of our times.

\section{NOTES}

$112^{\text {th }}$ Conference of the international Association of Visual Semiotics, Visual semiotics goes cognitive. Lund, August 22-24, 2019.

2 They were found in 1627, 1910 and 1931. Other runestones have been placed on Lund's University campus close by.

3 https://www.skissernasmuseum.se/en/exhibitions/kommande utst\%C3\%A4llning/The paste 
up is a portrait of Maram from Syria. This work is what was left in the museum after her site-specific solo exhibition on Skissernas in 2017.

4 Since the work is made and displayed inside the museum it cannot be called a real street art piece, thus I call it here a representation of a street art piece. This will be further explained later in this text.

5 A piano was also permanently placed there, with a humorous close to ironic touch included: on top of it a sign informs the visitors that this item is 'the grand piano'.

6 One might trace some similarities with the canvases and the commissioned murals that the famous Keith Harring did in the early 80 s.

7 In a photograph that Brassai took in Barcelona, 1955.

8 Details about Sweden's zero-tolerance in Jacob Kimvall's PhD dissertation, also published in Kimvall, Jacob. 2014. The G-word: virtuosity and violation, negotiating and transforming graffiti. Årstra, Sweden: Dokument Press

9 They are political in their initial action/praxis but this is just a first stage. I would argue that beyond that there is a multitude of scales and volumes in how the the messages, the artistic perspective and even the political consciousness are incorporated in the political.

10 Although it might sound like a generalization to speak about all the various forms of leaving a trace in public space and their several messages incorporated all in one, the least that can be said about their marks is that they also are a kind of 'semiotic guerilla warfare', borrowing here from the way Hebdige quoted Eco (1972) in his seminal work on subcultures. The signs and signifiers themselves leave a serious amount of information to be collected and further investigated. Hebdige, Dick, 1979, Subculture. The meaning of style

11 Of particular interest is the Urban Creativity Conference sticker (of a conference held at the University of Lund) which is written in marker-tag styled fonts. A tag was handwritten, printed on a sticker and then placed in public space.

12 For instance, exhibitions such as the recent Spring Torrents, Harvard Strike posters, Spring 1969, Thessaloniki State Museum of Contemporary Art, 2018.

13 Skissernas is located inside the Lund University campus and many of the streets examined here are also part of it.

14 Papaspyrou, Rena, Paparounis, Mihalis, \& State Museum of Contemporary Art (Greece). (2011)..

15 Tanizaki, Junichiro, 1977. In praise of shadows. New Haven, Conn: Leete's Island Books. Originally published in 1933.

16 'Le 29 juillet 1835, Victor Hugo grava son nom et celui de Juliette Drouet au donjon de Septmonts.' fr.geneawiki.com/index.php/02706 - Septmonts

17 For further details on Byron's story at Chillion: Hoffman, Detlef, 2019. "2000 years of Graffiti or each age has the walls it deserves", in Boulevard, in trespassing and culture, 2019 Frankfurt: Boulevard. First published in Graffiti: Tätowierte Wände, 1985. Bielefeld: AJZ Druck \& Verlag GmbH 
18 In an interview in www.subwayoutlaws.com. The interviewed does not reveal his real name but only his partner's who won the price together with. He leaves a little 'homework task' for the reader who is really interested in finding out his real name and in the same respect it is left open here as well.

19 For example in the exhibition Born in the Streets - Graffiti presented at the Fondation Cartier pour l'art contemporain à Paris from July 7 to November 29, 2009. Access to the image: https://www.nyhistory.org/exhibit/graffiti-door

20 City as canvas: Martin Wong's collection, City Museum of New York, 2015.

21 Baudrillard, Jean. 1993. Symbolic Exchange and Death. London: Sage Publications p.76. First published: 1976. Original essay: 'KOOL KILLER, or The Insurrection of Signs' (1975) 22 lbid. p.80.

23 Novy, Dumar. 2015. What Do One Million Tags Signify? Berlin: Possible books. pp. 28-31

24 Ceci n'est pas un graffiti. Episode 8/10. Ich bin ein Street Artiste. (2017) https://www.arte.

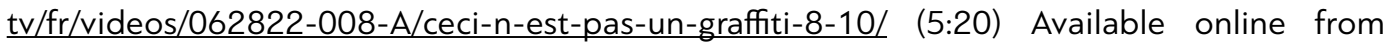
$16 / 03 / 2017$ to $30 / 11 / 2019$

25 In the subway writers' own words in books such as Schmidlapp, David and Phase 2 eds. 1996. Style: writing from the underground: ${ }^{\circledR}$ evolutions of aerosol linguistics. Viterbo: Stampa alternativa/ Nuovi equilibri \& IGTimes, and Fliesher, Alan and Paul lovino with introduction by Phase 2. 2012. Classic Hits: New York's Pioneering Subway Graffiti Writers, Stockholm: Dokument Press.

26 According to both graffiti writers and researchers such Joe Austin, Craig Castleman and Ivor Miller.

27 Originally published in partial letters - reports of his travels in Chicago Daily and then printed in Harrison, Carter H. 1889. A race with the sun; or, A sixteen months' tour from Chicago around the world. New York: G.P. Putnam's sons. p. 295 https://archive.org/stream/racewithsunorsix0Oharr/racewithsunorsixOOharr djvu.txt . First read about Harrison in researcher's Roger O. De Keersmaecker personal website http://www.egypt-sudan-graffiti.be/ .

28 McCormick, Matt, The Subconscious Art of Graffiti Removal (USA, 2001, 16 min). Also released in Barenthin Lindblad, Tobias, and Macarena Dusant. 2009. Metagraffiti: graffiti art films. Stockholm: Dokument Förlag

29 A larger, usually linear, format of tagging/graffiti.

30 International annual book fair dedicated to publications on graffiti, street art and the neighboring fields. http://unlockfair.com/

31 Rail experimental - Belgian train worker art. 2019. Belgium: Nokkio Institute of Zines https:// hitzerot.com/product/rail-experimental/ Another recent publication that adds insight to the aesthetics of erased graffiti is the book Buffantgarde whose title is a wordplay of the words buff (erasing) and avant-garde. Stavrov, Konstantin, and Oleg Kuzneov. 2018. Buffantgarde. Saint Petersburg: Invalid books. The most recent book including relevant content was published in 
Sweden in October 2019: Madsen, Carsen, and Claus Peder Pedersen. 2019. Paintworks. Jonas Georg Christensen og Peter Olsen. Årstra, Sweden: Dokument Press

32 Out of Necessity. 2019. Antwerpen: Nokio Institute of Zines

33 The documentation is what actually creates the recorded history in graffiti. For sure the oral history is a fundamental factor for each community's bonds and each scene's development but on the other hand it has its limitations: the stories will one day be forgotten and/or die if the oral history will not become documented in a written format.

34 The ones that happen in the streets are the only real ones, and not those works that are painted or installed on canvases on and/or inside the museum and gallery walls. The latter are representations of the actual ones. After all, galleries and museums are not the streets. What happens in the sanctioned places, as well as on legally commissioned walls lacks the fundamental act of appropriating space, doing it without permission.

35 As director of Unlock Book Fair Javier Abarca explained in the book launch, in Amsterdam 2018.

36 A photograph of that interior wall is featured on the back cover of Manco, Tristan. 2004. Street logos. London: Thames \& Hudson.

37 Even if it is not about the aesthetics, designwise an object such as the telecommunications boxes will most possibly disappear from the city landscape because it will not be needed anymore. As it has happened with most telephone booths they will only be regarded as an object of the past.

\section{REFERENCES}

Abarca, Javier and Thomas Chambers 2018. Punk Graffiti Archives: Madrid. Madrid: Urbanario. Barenthin Lindblad, Tobias, and Macarena Dusant 2009. Metagraffiti: graffiti art films. Stockholm: Dokument Forlag.

Baudrillard, Jean 1993. Symbolic Exchange and Death. London: Sage Publications.

Chandes, Herve 2009. Born in the streets: graffiti. Paris: Fondation Cartier pour l'art contemporain.

Haglund, Elisabet, Eva Zetterman, Pedro da Cruz, Malin Enarsson, and Hector Armando Herrera 2010. Skissernas museum and Mexico. Lund: Skissernas museum.

Harrison, Carter H. 1889. A race with the sun; or, A sixteen months' tour from Chicago around the world. New York: G.P. Putnam's sons

Hebdige, Dick 1979, Subculture. The meaning of style. London: Routledge.

Hoffman, Detlef 2019. "2000 years of Graffiti or each age has the walls it deserves", in Boulevard, in trespassing and culture, 2019 Frankfurt: Boulevard. 
Kimvall, Jacob. 2014 The G-word: virtuosity and violation, negotiating and transforming graffiti.

Arstra, Sweden: Dokument Press.

Madsen, Carsen, and Claus Peder Pedersen 2019. Paintworks. Jonas Georg Christensen og Peter Olsen. Arstra, Sweden: Dokument Press.

Manco, Tristan 2004. Street logos. London: Thames \& Hudson.

Novy, Dumar 2015. What Do One Million Tags Signify? Berlin: Possible books.

Out of Necessity. 2019. Antwerpen: Nokio Institute of Zines.

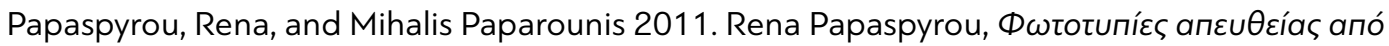

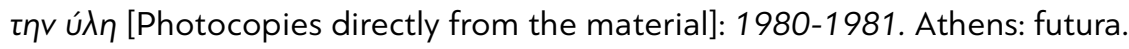

Rail experimental - Belgian train worker art. 2019. Antwerpen: Nokio Institute of Zines.

Schmidlapp, David and Phase 2 1996. Style: writing from the underground: Revolutions of aerosol linguistics. Viterbo: Stampa alternativa/ Nuovi equilibri \& IGTimes

Skissernas Museum 2019. Guide book / Loan Copy Lund: Skissernas.

Stavrov, Konstantin, and Oleg Kuzneov 2018. Buffantgarde. Saint Petersburg: Invalid books.

Tanizaki, Junichiro 1977. In praise of shadows. New Haven, Conn: Leete's Island Books.

\section{FIGURES}

All photographs by Orestis Pangalos except 8 and 12.

Orestis Pangalos PhD, is an architect, artist, and researcher. He is currently teaching Art, History of Art, Visual and Cultural Studies courses in Postgraduate Programs at Aristotle University of Thessaloniki.

Email: o.pangalos@gmail.com 